\title{
Desempenho produtivo, características de carcaça e avaliação econômica de bovinos cruzados, castrados e não-castrados, terminados em pastagens de Brachiaria decumbens
}

\author{
[Productive performance, carcass characteristics and economic evaluation of castrated and non-castrated \\ crossbred bovines finished in Brachiaria decumbens pastures]

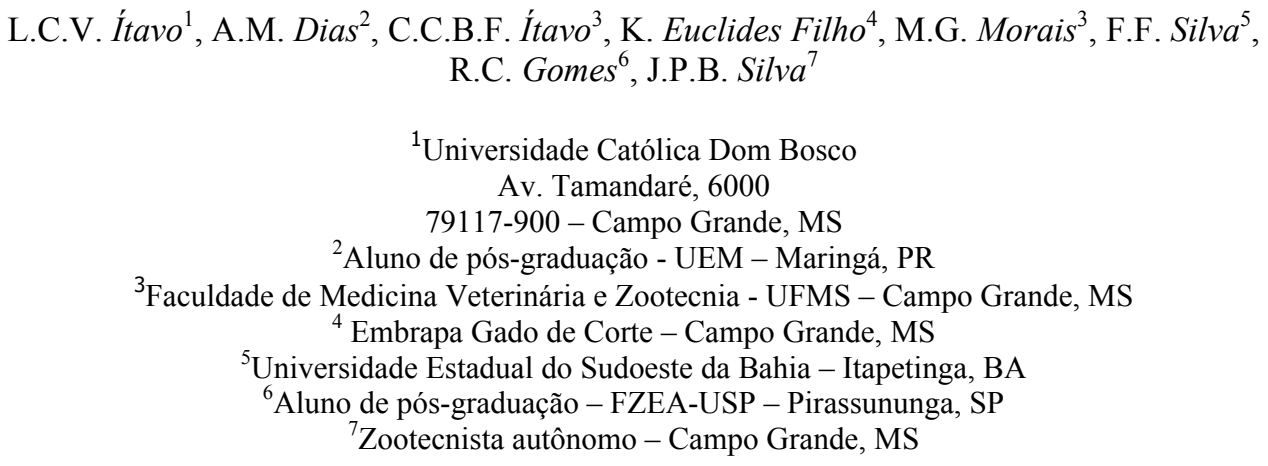

\section{RESUMO}

Avaliou-se o efeito da castração sobre o desempenho produtivo e sobre as características de carcaça e realizouse a avaliação econômica de bovinos terminados em pastagens de Brachiaria decumbens. Foram utilizados oito novilhos Canchim-Nelore com 14 meses de idade, sendo quatro animais castrados e quatro não-castrados, com média de peso corporal de $273,2 \mathrm{~kg}$. O delineamento foi inteiramente ao acaso com quatro repetições por tratamento. Os animais receberam, diariamente, $0,7 \%$ do PC de suplemento proteíco-energético e foram abatidos aos 26 meses de idade. $\mathrm{O}$ peso de abate e o ganho médio diário (GMD) diferiram entre castrados e não-castrados, com médias de 441,0 e $482,2 \mathrm{~kg}$ e 0,6 e $0,7 \mathrm{~kg} /$ dia, respectivamente. Não houve efeito da castração sobre as características avaliadas, com exceção do peso de abate, do peso da carcaça quente, 252,3 versus $229,9 \mathrm{~kg}$, da cor da carne, 3,25 versus 4,50 pontos e da espessura da gordura subcutânea, 0,6 versus $1,4 \mathrm{~mm}$, respectivamente, para não-castrados e castrados. A lucratividade por animal e por hectare foi de $14,5 \mathrm{e}$ $15,8 \%$ para não-castrados e 4,5 e $5,8 \%$ para castrados, respectivamente. Sugere-se a utilização de bovinos nãocastrados suplementados em pastagens de Brachiaria decumbens.

Palavras-chave: bovino, castração, custos, lucratividade, suplementação

\begin{abstract}
The effect of the castration on the productive performance and carcass characteristics was studied, as well as, the economic evaluation of finished bovines raised on Brachiaria decumbens pastures. Eight Canchim-Nellore steers aging 14-months-old were used, being four castrated and four non-castrated, averaging $273.2 \mathrm{~kg}$ body weight. It was used a completely randomized design with four repetitions per treatment. The animals received $0.7 \%$ of their body weight of proteic-energetic supplement and were slaughtered at 26 months of age. The weight at slaughtering and the average daily weight gain differed between castrated and non-castrated, averaging 441.0 and $482.2 \mathrm{~kg}$, and 0.6 and $0.7 \mathrm{~kg} /$ day, respectively. No effects of the castration on carcass characteristics were observed, except for weight of hot carcass, 252.3 versus 229.9kg; meat color, 3.25 versus 4.50 points; and subcutaneous fat thickness, 0.6 versus $1.4 \mathrm{~mm}$; respectively, for non-castrated and castrated. The profitabilities per animal and hectare were 14.5 and $15.8 \%$ for non-castrated and $4.5 \%$ and $5.8 \%$ for castrated, respectively. It is suggested the raised of non-castrated bovines supplemented on Brachiaria decumbens pastures.
\end{abstract}

Keywords: beef cattle, castration, costs, profitability, supplementation

Recebido em 28 de março de 2008 


\section{INTRODUÇÃO}

A terminação de bovinos é feita habitualmente em pastagens, o que resulta, muitas vezes, em abate tardio. Sabe-se que a castração apresenta algumas vantagens relacionadas com o melhor manejo do gado, com a lucratividade do sistema e com a maior aceitação do produto pelo mercado. No Brasil, tal prática é, tradicionalmente, realizada em animais destinados ao abate. Seideman et al. (1982) afirmaram que animais não-castrados produzem carcaças com maior proporção de carne comercializável e com menor teor de gordura.

Restle et al. (1997) demonstraram a superioridade do desempenho de animais nãocastrados, porém afirmaram que tal superioridade se torna mais relevante em sistemas de produção intensiva, em que se busca o peso de abate em menor tempo. Segundo Euclides et al. (1997), um dos fatores responsáveis pela baixa produção bovina nos trópicos é a deficiência nutricional resultante, principalmente, da característica da produção forrageira. Há de se destacar que a bovinocultura do estado de Mato Grosso do Sul ocorre, principalmente, em pastagens de baixa qualidade, onde predominam as gramíneas do gênero Brachiaria.

Com a redução da idade de abate, surge nova perspectiva de produção de carne a partir de machos não-castrados. Esse procedimento é adotado há muito tempo em vários países europeus, onde grande parte da carne consumida é proveniente de bovinos não-castrados, abatidos com idade inferior a dois anos (Restle et al., 2000a,b). Ítavo e Silva (2001), ao revisarem o assunto, concluíram que o nível nutricional dos animais influencia a adoção da castração, isto é, quando os animais mantidos sob regime alimentar de bom nível nutricional são abatidos com menos de 24 meses de idade, a castração é desnecessária. Nesse sentido, a castração seria importante para animais abatidos tardiamente, favorecendo, assim, o manejo, a engorda e a qualidade da carne, no que diz respeito à maciez.

Reeves et al. (2004) verificaram maior peso ao abate, maior rendimento de carcaça e maior proporção de músculo na carcaça dos animais não-castrados e maior proporção de gordura na carcaça e maior marmorização na carne dos animais castrados. Apesar de a utilização de animais não-castrados para o abate trazer benefícios para o produtor, devido à maior velocidade de crescimento em relação aos castrados (Restle et al., 1999), ainda restam dúvidas com relação às características de carcaça dos mantidos não-castrados (Vaz et al., 1999).

Climaco et al. (2006) observaram que animais não-castrados apresentam maiores pesos $\mathrm{e}$ ganhos de peso do que os castrados, sendo abatidos em menor tempo ou idade, porém os pesos e rendimentos dos cortes comerciais das carcaças foram similares entre os dois grupos. Vittori et al. (2006), ao estudarem as características de carcaça de bovinos castrados e não-castrados, verificaram que os animais nãocastrados apresentaram carcaças mais pesadas, com maior rendimento, maior proporção de tecido muscular, porém com espessura de gordura subcutânea semelhante à dos castrados.

Assim, este estudo teve por objetivo comparar o desempenho produtivo, as características de carcaça e a viabilidade econômica do sistema de criação de novilhos castrados e não-castrados em pastagens de Brachiaria decumbens.

\section{MATERIAL E MÉTODOS}

O experimento foi realizado no período de dezembro de 2001 a dezembro de 2002, totalizando 360 dias. Foram utilizados oito novilhos F1 (Canchim x Nelore), com média de idade inicial de 14 meses. Todos os animais eram oriundos do mesmo rebanho, nascidos na mesma época de parição e, exceto pela castração, foram mantidos sob as mesmas condições de manejo e alimentação. Os animais, com média de peso corporal (PC) de $225,25 \mathrm{~kg}$, foram divididos aleatoriamente em dois grupos, com quatro animais cada, castrados e não-castrados, os quais apresentaram médias de peso de 226,25 e $224,25 \mathrm{~kg}$, respectivamente. A castração foi realizada aos 10 meses de idade pelo método tradicional e consistiu na ablação testicular. Os animais permaneceram em quatro piquetes, com média de 0,58 hectares cada, formados por pastagem de Brachiaria decumbens, providos de bebedouro e comedouro cobertos.

Para a avaliação de desempenho, foram estudados: peso corporal (PC) inicial e final, ganho de peso total (GPT) e ganho médio diário (GMD). Para tal, os animais foram pesados, 
individualmente, a cada 28 dias. Foi fornecido, em média, $0,7 \%$ do $\mathrm{PC}$ em matéria seca (MS) de suplemento com $17,3 \%$ de proteína bruta (PB) e $72,9 \%$ de nutrientes digestíveis totais (NDT), uma vez ao dia.

A participação dos ingredientes no concentrado e os teores de matéria seca (MS), de nutrientes digestíveis totais (NDT), de proteína bruta (PB), de cálcio $(\mathrm{Ca})$ e de fósforo $(\mathrm{P})$, e os custos $(\mathrm{R} \$ / \mathrm{kg}$ de matéria natural) são apresentados na Tab. 1. As análises laboratoriais foram realizadas segundo metodologia descrita por Silva e Queiroz (2002).

A cada pesagem, os animais foram colocados em piquetes diferentes dos que estavam, a fim de eliminar possíveis efeitos de piquete. A produção de MS de folha disponível foi determinada mediante coleta de amostras a cinco centímetros do solo (quatro amostras de $0,25 \mathrm{~m}^{2}$ por piquete), separando-se as frações senescente e verde (viva). Da fração viva, retirou-se uma subamostra para separação de folha (lígula+bainha) e colmo (haste).

Tabela 1. Ingredientes (\%) no concentrado, teores de matéria seca (MS), nutrientes digestíveis totais (NDT), proteína bruta $(\mathrm{PB})$, cálcio $(\mathrm{Ca})$ e fósforo $(\mathrm{P})$, e custos $(\mathrm{R} \$ / \mathrm{kg}$ de matéria natural - $\mathrm{MN})$

\begin{tabular}{|c|c|c|c|c|c|c|c|}
\hline \multirow{2}{*}{ Ingrediente } & \multirow{2}{*}{$\%$} & \multirow{2}{*}{ MS (\%) } & NDT & $\mathrm{PB}$ & $\mathrm{Ca}$ & $\mathrm{P}$ & \multirow{2}{*}{$\begin{array}{l}\mathrm{R} \$ / \mathrm{kg} \\
\text { de } \mathrm{MN}\end{array}$} \\
\hline & & & \multicolumn{4}{|c|}{$\%$ da MS } & \\
\hline Aveia & 24 & 88,39 & 78,51 & 13,96 & 0,10 & 0,30 & 0,28 \\
\hline Milho quebrado & 20 & 91,60 & 86,40 & 9,82 & 0,13 & 0,26 & 0,20 \\
\hline Farelo de arroz & 20 & 87,91 & 87,91 & 16,79 & 0,15 & 0,99 & 0,20 \\
\hline Farelo de soja & 16 & 88,56 & 81,04 & 47,64 & 0,40 & 0,71 & 0,50 \\
\hline Farelo de trigo & 9 & 88,87 & 79,50 & 14,41 & 0,11 & 1,54 & 0,28 \\
\hline Calcário calcítico & 3 & 98,00 & 0 & 0 & 38,00 & 0,02 & 1,85 \\
\hline Mineral & 3 & 99,00 & 0 & 0 & 20,00 & 8,00 & 0,80 \\
\hline Rumenúcleo & 4 & 98,00 & 0 & 0 & 27,00 & 5,00 & 0,80 \\
\hline Alho em pó & 1 & 98,00 & 0 & 0 & 39,00 & 0,04 & 0,80 \\
\hline Total & 100 & 89,23 & 72,92 & 17,33 & 1,29 & 0,64 & 0,38 \\
\hline
\end{tabular}

Para a avaliação das características de carcaça, o abate foi realizado em frigorífico industrial quando os animais apresentaram idade média de 26 meses e peso corporal médio de $461,77 \mathrm{~kg}$. As características de carcaça avaliadas foram: comprimento, conformação, maturidade fisiológica, cor, textura, marmoreio e espessura de gordura subcutânea, realizadas conforme Muller (1987). A avaliação da carcaça ocorreu após 24 horas do resfriamento, a $1^{\circ} \mathrm{C}$, e constou de avaliações objetivas, pesagens e medições de espessura de gordura, e subjetivas, conformação, maturidade fisiológica, cor, testura e marmoreio. A partir de um corte transversal na $12^{\mathrm{a}}$ vértebra torácica, foram avaliados cor, textura e marmoreio da carne, assim como mediu-se a gordura de cobertura e desenhou-se o contorno do músculo Longissimus, a saber: (a) conformação: escala de pontuação de 1 a 18 , sendo 1 a $3=$ côncava; 4 a $6=$ sub-retilínea; 7 a $9=$ retilínea; 10 a $12=$ subconvexa; 13 a $15=$ convexa e 16 a 18= hiperconvexa (Muller, 1987); (b) maturidade fisiológica: escala de pontuação conforme a ossificação das cartilagens variando de níveis de mais a menos (Muller, 1987); (c) cor da carne: escala de pontuação conforme a intensidade, sendo: 1= escuro; $2=$ vermelho escuro; 3= vermelho levemente escuro; 4= vermelho e 5= vermelho vivo (Muller, 1987); (d) textura da carne: escala de pontuação conforme as fibras musculares: $1=$ muito grosseira; $2=$ grosseira; $3=$ levemente grosseira; $4=$ fina e $5=$ muito fina (Muller, 1987); (e) grau de marmoreio: escala de pontuação conforme o grau de deposição de gordura intramuscular: 1 a $3=$ traços; 4 a $6=$ leve; 7 a $9=$ pequeno; 10 a $12=$ médio; 13 a $15=$ moderado e 16 a $18=$ abundante (Muller, 1987).

Para a avaliação econômica do sistema de produção (Tab. 2), os resultados obtidos foram simulados para 12 anos; todos os preços foram deflacionados tendo como base o mês de setembro de 2002, de acordo com Feijó (1999) e Ribeiro (2000). 


\section{Ítavo et al.}

Tabela 2. Composição do custo total anual dos investimentos em benfeitorias, instalações e custos operacionais

\begin{tabular}{|c|c|c|c|c|c|c|}
\hline & \multirow[b]{2}{*}{ Unidade } & \multirow[b]{2}{*}{ Custo } & \multirow[b]{2}{*}{ COCI } & \multicolumn{2}{|c|}{ Depreciação } & \multirow[b]{2}{*}{ CND } \\
\hline & & & & Anos & Valor & \\
\hline \multicolumn{7}{|c|}{ Investimentos } \\
\hline Mangueiro $^{1}$ & - & $42.087,41$ & & - & $1.089,78$ & $1.089,78$ \\
\hline Casa de empregado & - & $8.000,00$ & & 50 & 99,42 & 99,42 \\
\hline Formação $^{2}$ & ha & $41.620,00$ & & 5 & $5.741,23$ & $5.741,23$ \\
\hline Máquinas e Implementos & - & $16.500,00$ & & 15 & 683,51 & 683,51 \\
\hline Eqüinos & Animal & $1.000,00$ & & 15 & 43,73 & 43,73 \\
\hline Terra & ha & $139.709,51$ & & - & 0,0 & 0,0 \\
\hline Cerca do mangueiro $^{3}$ & - & $3.282,63$ & & 25 & 81,82 & 81,82 \\
\hline Cerca do piquete $^{4}$ & - & $11.257,88$ & & 25 & 277,21 & 277,21 \\
\hline Total & & $263.457,43$ & & & $8.016,70$ & $8.016,70$ \\
\hline \multicolumn{7}{|c|}{ Despesas } \\
\hline Ração & $\mathrm{kg}$ & $98.902,94$ & $2.967,09$ & & 0,0 & $2.967,09$ \\
\hline Hora-máquina & $\mathrm{H} / \mathrm{m}$ & 988,67 & 29,66 & & 0,0 & 29,66 \\
\hline Impostos 5 & - & 778,91 & 23,37 & & 0,0 & 23,37 \\
\hline Mão-de-obra ${ }^{6}$ & - & $4.752,77$ & 142,58 & & 0,0 & 142,58 \\
\hline Bovinos & Animal & $106.950,00$ & $3.208,50$ & & 0,0 & $3.208,50$ \\
\hline Medicamentos & - & $2.620,11$ & 78,60 & & 0,0 & 78,60 \\
\hline Formação & ha & $5.746,98$ & 172,41 & & & 172,41 \\
\hline Total & & $220.740,38$ & $6.622,21$ & & & $6.622,21$ \\
\hline
\end{tabular}

Custo: valor de mercado.

COCI: custo de oportunidade do capital investido (valor do bem * 3\%).

Depreciação: [valor do bem - (valor do bem * 0.10)]/vida útil.

CND: custo não desembolsável (somatório do custo de oportunidade + depreciação).

Consideraram-se:

${ }^{1}$ Preço dos componentes (tábuas, mourões, barras de rosca, arruelas, portões, concreto $*$ quantidade $*$ valor de mercado) + tronco de contenção + balança + galpão + mão-de-obra.

Preço do tronco: R \$ 3.700,00; balança: R \$ 3.400,00; galpão: R\$ 15.000,00.

Mão-de-obra: dois homens ( $\mathrm{R} \$ 1.200,00=80$ diárias de $\mathrm{R} \$ 15,00)$.

${ }^{2}$ Valor de insumos (calcário: 4 toneladas/ha * 100ha * R \$ 47,50; + adubo: 400kg/ha * 100ha* R \$ 500) +operações mecanizadas (calagem: R \$ 15,72 valor hora máquina/ha * 100ha; + adubação: R \$ 10,48/ha * 100ha).

${ }^{3}$ Preço dos componentes (postes + balancins + mourões + arame + porteiras * quantidade) + mão-de-obra (já inclusa no mangueiro).

${ }^{4}$ Preço dos componentes (postes + balancins + mourões + arame + porteira) + mão-de-obra ( $\$ 600,00=20$ diárias).

${ }^{5}$ ITR - 50 - 200ha (R\$ 0,46) + CNA (R\$ 35,29) + FUNDERSUL (R\$ 743,16).

${ }^{6}$ Taxa de juros de $6 \% /$ ano.

A receita do sistema constituiu basicamente o valor de venda dos animais. O valor de mercado da arroba foi obtido pela média praticada na praça de Campo Grande-MS, durante o mês de outubro de 2002 (R\$ 52,00). O preço de compra dos animais foi obtido pela média de preços encontrados no Anualpec (Anuário..., 2002), referentes à média do mês de fevereiro de 2001 ( R\$ 310,00).

Para análise econômico-financeira dos dois grupos (castrados e não-castrados), foram utilizados os critérios do valor presente líquido
(Euclides et al., 1997; Feijó, 1999; Ribeiro, 1999), da lucratividade por animal (Aguiar et al., 2001) e da lucratividade por hectare. Os cálculos foram realizados por meio de planilhas eletrônicas (Microsoft Excel), utilizando-se o fluxo de caixa dos dois sistemas (dois grupos) de produção em um período de 12 anos.

Para os dados de desempenho e de características de carcaça, e para a avaliação econômica, utilizou-se o SAEG (Sistema..., 1997). As médias foram comparadas em $5 \%$ de significância pelo teste $\mathrm{F}$. 


\section{RESULTADOS E DISCUSSÃO}

As médias de disponibilidade de MS de folhas e a porcentagem dos componentes da forragem (\% de material vivo, senescente, hastes e folhas) são apresentadas na Tab. 3.

Houve diferença significativa entre as disponibilidades de MS/ha, sendo que o piquete 3 apresentou a maior média, $6.862,7 \mathrm{~kg}$ de $\mathrm{MS} /$ ha. Há de se destacar que este piquete apresentou maior área, $7.932 \mathrm{~m}^{2}$, fato que refletiu na disponibilidade total, por favorecer maior área para seleção do pastejo dos animais. Para a obtenção de suprimento abundante de forragem de boa qualidade durante o verão, em que há crescimento intenso das forrageiras, preconiza-se $\mathrm{o}$ uso intercalado de manejo para qualidade e quantidade (Paulino et al., 2001). Assim, visualizam-se ganhos de peso em torno de
$1,2 \mathrm{~kg} /$ animal/dia no período de dezembro a fevereiro (Paulino et al., 2002). Todavia, durante o período de inverno, em que há restrições de água e luminosidade, as forrageiras tropicais não apresentam crescimento, podendo interferir negativamente no desempenho animal.

As médias de haste e folhas nos piquetes foram 61 e 39\%, respectivamente. Tais resultados podem interferir negativamente nos resultados de desempenho, pois essa quantidade de colmos limitaria o consumo de forragem, justificando a necessidade de suplementação. Estes resultados assemelham-se aos apresentados por Ítavo et al. (2008) para o período de inverno, com pastagens de Brachiaria brizantha. Segundo Silva (2000), o nível nutricional pode indicar ou não o uso da castração, pois, quando o plano nutricional é alto e o abate ocorre antes dos 24 meses, a castração é desnecessária.

Tabela 3. Porcentagem média de material senescente e vivo (verde), hastes, folhas (\% do material vivo) e disponibilidade de matéria seca (MS) total e de folhas por piquete e por hectare dos piquetes experimentais

\begin{tabular}{lccccc} 
& \multicolumn{4}{c}{ Piquete } & \multicolumn{2}{c}{$\mathrm{CV}$} \\
\cline { 2 - 5 } & 1 & 2 & 3 & 4 & - \\
\hline Área $\left(\mathrm{m}^{2}\right)$ & 4.597 & 5.039 & 7.932 & 5.639 & - \\
Material senescente (\%) & $63,0 \mathrm{a}$ & $58,1 \mathrm{a}$ & $57,1 \mathrm{a}$ & $61,9 \mathrm{a}$ & 13,35 \\
Material vivo (\%) & $37,0 \mathrm{a}$ & $41,9 \mathrm{a}$ & $42,9 \mathrm{a}$ & $38,1 \mathrm{a}$ & 14,54 \\
Hastes (\% do mat. vivo) & $60,0 \mathrm{a}$ & $61,5 \mathrm{a}$ & $60,0 \mathrm{a}$ & $62,5 \mathrm{a}$ & 13,45 \\
Folhas (\% do mat. vivo) & $40,0 \mathrm{a}$ & $38,5 \mathrm{a}$ & $40,0 \mathrm{a}$ & $37,5 \mathrm{a}$ & 15,64 \\
kg MS-total/piquete & $2.433,7 \mathrm{~b}$ & $3.062,9 \mathrm{~b}$ & $5.443,5 \mathrm{a}$ & $2.321,9 \mathrm{~b}$ & 9,32 \\
$\mathrm{~kg} \mathrm{MS}-$-verde/piquete & $901,4 \mathrm{~b}$ & $1.284,3 \mathrm{~b}$ & $2.333,1 \mathrm{a}$ & $884,7 \mathrm{~b}$ & 15,47 \\
kg MS-total/hectare & $5.294,1 \mathrm{~b}$ & $6.078,4 \mathrm{ab}$ & $6.862,7 \mathrm{a}$ & $4.117,6 \mathrm{c}$ & 16,57 \\
\hline
\end{tabular}

Médias seguidas por letras iguais na linha não diferem pelo teste Tukey $(\mathrm{P}>0,05)$.

CV: coeficiente de variação.

$\mathrm{Na}$ Tab. 4, são apresentados os PC inicial e final, o GPT e o GMD em função do tratamento.

Houve diferença significativa $(\mathrm{P}<0,05)$ para o $\mathrm{PC}$ final. Este resultado é proveniente da diferença $(\mathrm{P}<0,05)$ observada nas médias de GMD, 0,59 e $0,71 \mathrm{~kg} / \mathrm{dia}$, respectivamente, para os animais castrados e não-castrados, e assemelha-se aos obtidos por Restle et al. (2000a), que avaliaram o consumo alimentar e o ganho de peso na fase de crescimento de animais não-castrados ou castrados dos grupos genéticos Charolês, Nelore e seus cruzamentos, e concluíram que animais não-castrados apresentaram maior GMD e foram mais eficientes na transformação de alimento em ganho de peso que os castrados.

Tabela 4. Médias de peso corporal (PC) inicial e final, ganho de peso total (GPT), ganho médio de peso diário (GMD) em função dos tratamentos

\begin{tabular}{lccc}
\hline Variável & Castrado & Não-castrado & CV \\
\hline PC inicial (kg) & $226,25 \mathrm{a}$ & $224,25 \mathrm{a}$ & 10,59 \\
PC final (kg) & $441,00 \mathrm{~b}$ & $482,25 \mathrm{a}$ & 8,52 \\
GPT (kg) & $214,75 \mathrm{~b}$ & $258,00 \mathrm{a}$ & 16,94 \\
GMD (kg/dia) & $0,59 \mathrm{~b}$ & $0,71 \mathrm{a}$ & 16,94 \\
\hline
\end{tabular}

Médias seguidas por letras distintas na linha diferem entre si pelo teste $\mathrm{F}(\mathrm{P}<0,05)$. 
Cosgrove et al. (1996) relataram crescimento mais rápido de animais não-castrados, 12,3 e $19,2 \%$, que de castrados, durante as fases de recria e engorda, respectivamente, e GMD de 1,3 e $1,0 \mathrm{~kg}$ para não-castrados e castrados, respectivamente. Entretanto, vale ressaltar que a avaliação conduzida por esses autores foi em confinamento, por um período experimental de 103 dias, o que pode justificar a diferença. Vários autores (Restle et al., 1996; Restle et al., 1997) demonstraram a superioridade do desempenho de animais não-castrados, porém afirmaram que tal superioridade se torna mais relevante em sistemas de produção intensiva, em que se busca o peso de abate em menor espaço de tempo.

O maior desempenho por parte dos animais nãocastrados foi favorecido pelo fato de serem menos exigentes em proteínas para mantença e ganho que animais castrados (Valadares Filho et al., 2006). Estes resultados estão de acordo com os de Vittori et al. (2007), que avaliaram desempenho produtivo de bovinos de diferentes grupos raciais, castrados e não-castrados em fase de terminação, e verificaram que o peso de abate dos animais não-castrados foi mais elevado que o dos castrados (497 vs $447 \mathrm{~kg}$ ). Isto pode estar relacionado ao fato de que a produção hormonal proveniente dos testículos tenha apresentado maior efeito na deposição de músculo na fase de crescimento, proporcionado pelo melhor nível de alimentação, como citado por Restle et al. (1994). Animais não-castrados iniciam o processo de deposição de gordura mais tarde e, normalmente, são abatidos com pesos mais elevados.

Climaco et al. (2006), ao avaliarem o desempenho de animais castrados e nãocastrados suplementados em pastagens, verificaram que os não-castrados apresentaram maior ganho de peso dos 14 meses até o abate. $\mathrm{O}$ GMD dos animais não-castrados foi de $0,50 \mathrm{~kg} /$ dia e o dos castrados, $0,41 \mathrm{~kg} / \mathrm{dia}$. Esses valores são mais baixos que os apresentados neste trabalho, porém a avaliação desses autores foi realizada durante o inverno.

$\mathrm{Na}$ Tab. 5, são apresentados médias de peso de abate, rendimento de carcaça, peso de carcaça quente, comprimento de carcaça, conformação, maturidade fisiológica, cor, textura, marmoreio, espessura de gordura em função dos tratamentos.

Tabela 5. Características de carcaça de novilhos F1 Canchim x Nelore, terminados em pastagem de Brachiaria decumbens, em função do tratamento

\begin{tabular}{|c|c|c|c|}
\hline Variável & Castrado & Não-castrado & $\mathrm{CV}(\%)$ \\
\hline Peso ao abate $(\mathrm{kg})$ & $441,00 b$ & $482,55 a$ & 8,52 \\
\hline Rendimento (\%) & $52,13 \mathrm{a}$ & $52,29 a$ & 3,26 \\
\hline Peso de carcaça quente & $229,90 b$ & $252,30 \mathrm{a}$ & 8,35 \\
\hline Comprimento $(\mathrm{cm})$ & $125 \mathrm{a}$ & $130 \mathrm{a}$ & 3,52 \\
\hline Conformação $^{1}$ & $12,5 \mathrm{a}$ & $13,0 \mathrm{a}$ & 8,47 \\
\hline Maturidade fisiológica $^{2}$ & $14,75 \mathrm{a}$ & $14,00 \mathrm{a}$ & 4,71 \\
\hline $\mathrm{Cor}^{3}$ & $4,50 \mathrm{a}$ & $3,25 b$ & 11,75 \\
\hline Textura $^{4}$ & $4,50 \mathrm{a}$ & $4,37 \mathrm{a}$ & 3,98 \\
\hline Marmoreio $^{5}$ & $6,75 a$ & $5,75 a$ & 28,92 \\
\hline Espessura da gordura (mm) & $1,38 \mathrm{a}$ & $0,62 b$ & 29,90 \\
\hline
\end{tabular}

Médias seguidas por letras distintas na linha diferem entre si pelo teste $\mathrm{F}(\mathrm{P}<0,05)$.

${ }^{1}$ Escala de pontuação de 1 a 18 , sendo: 1 a 3 = côncava; 4 a 6 = sub-retilínea; 7 a 9 = retilínea; 10 a $12=$ subconvexa; 13 a $15=$ convexa e 16 a 18= hiperconvexa (Muller, 1987).

${ }^{2}$ Escala de pontuação conforme a ossificação das cartilagens variando de níveis de mais a menos (Muller, 1987).

${ }^{3}$ Escala de pontuação conforme a intensidade, sendo: $1=$ escuro; 2 = vermelho escuro; 3 = vermelho levemente escuro; $4=$ vermelho e 5= vermelho vivo (Muller, 1987).

${ }^{4}$ Escala de pontuação conforme as fibras musculares: $1=$ muito grosseira; $2=$ grosseira; $3=$ levemente grosseira; $4=$ fina e $5=$ muito fina (Muller, 1987).

${ }^{5}$ Escala de pontuação conforme o grau de deposição de gordura intramuscular: 1 a $3=\operatorname{traços;~} 4$ a $6=1$ leve; 7 a $9=$ pequeno; 10 a 12= médio; 13 a 15= moderado e 16 a 18= abundante (Muller, 1987). 
Não houve diferença $(\mathrm{P}>0,05)$ para as características avaliadas, com exceção do peso de abate, do peso da carcaça quente, da cor da carne e da espessura de gordura subcutânea. Os animais não-castrados apresentaram maior peso de abate e maior peso de carcaça quente que os castrados, e estes maior espessura de gordura subcutânea que aqueles (Tab. 5). Para Restle et al. (2000b), animais não-castrados apresentam maiores pesos de abate e de carcaça, melhor conformação e mais músculo na carcaça que animais castrados, os quais mostram maior espessura e porcentagem de gordura na carcaça, e segundo Vaz e Restle (2000), animais nãocastrados apresentam carcaças com maior teor de músculo e menor quantidade de gordura que os castrados.

Para a maturidade fisiológica, resultados próximos de 15 pontos indicam melhor carcaça em função da precocidade do animal. Como os animais foram abatidos com idade média de 26 meses, as cartilagens, presentes nos processos espinhosos das vértebras torácicas e lombares, estariam dentro da classificação para considerálos animais precoces (Tab. 5). Houve efeito significativo para espessura de gordura subcutânea, e ambos, castrados e não-castrados, não alcançaram a espessura mínima de gordura exigida pelos frigoríficos, que é de $3 \mathrm{~mm}$. As condições de terminação a que foram submetidos os animais resultaram em menor espessura de gordura. Para o marmoreio, o valor médio de 6,25 indica uma classificação de apenas marmoreio leve.

$\mathrm{Na}$ Tab. 6, são apresentados os resultados da avaliação econômica por animal e por área, em função dos tratamentos. A castração influenciou significativamente na rentabilidade do sistema, sendo as respostas mais favoráveis ao grupo dos não-castrados.

A quantidade de carcaça produzida por animal e por hectare foi maior para os não-castrados. Estes resultados sugerem ser mais atrativa a criação de animais não-castrados destinados ao abate. Isto se confirma quando se observa a lucratividade por animal, 14,5 e $4,5 \%$, e por hectare, 15,8 e 5,8\%, para novilhos não-castrados e castrados, respectivamente. Essas diferenças a favor dos não-castrados estão de acordo com as relatadas na literatura, que apontam crescimento mais acelerado, melhor eficiência de uso do alimento (13\%) e maior ganho de peso diário para os não-castrados. Steen (1995) observou produção mais eficiente de carne nos animais não-castrados que nos castrados, com ganho $30 \%$ maior para os não-castrados.

Tabela 6. Avaliação econômica por animal e por hectare, em função do tratamento

\begin{tabular}{lccc}
\hline Variável & Não-castrado & Castrado & CV $(\%)$ \\
\hline Taxa de lotação (UA/hectare) & $3,39 \mathrm{a}$ & $3,04 \mathrm{~b}$ & 3,32 \\
kg de PC/hectare & $1.527,14 \mathrm{a}$ & $1.366,38 \mathrm{~b}$ & 7,23 \\
Arrobas produzidas/animal & $15,35 \mathrm{a}$ & $13,74 \mathrm{~b}$ & 8,42 \\
Arrobas produzidas/ha & $52,94 \mathrm{a}$ & $47,37 \mathrm{~b}$ & 8,36 \\
\hline & Rentabilidade por animal & 3,22 \\
Custo total (R\$) & $682,26 \mathrm{a}$ & $682,26 \mathrm{a}$ & 7,35 \\
Custo total/arroba (R\$) & $44,44 \mathrm{~b}$ & $49,67 \mathrm{a}$ & 9,45 \\
Receita/animal (R\$) & $798,35 \mathrm{a}$ & $714,31 \mathrm{~b}$ & 10,22 \\
Margem bruta (R\$) & $158,52 \mathrm{a}$ & $74,48 \mathrm{~b}$ & 10,11 \\
Margem líquida (R\$) & $116,09 \mathrm{a}$ & $32,05 \mathrm{~b}$ & 11,13 \\
Lucratividade (\%) & $14,53 \mathrm{a}$ & $4,50 \mathrm{~b}$ & 3,21 \\
\hline & Rentabilidade por hectare & 8,25 \\
Custo total (R\$) & $2.319,01 \mathrm{a}$ & $2.319,01 \mathrm{a}$ & 9,32 \\
Custo total/arroba (R\$) & $43,80 \mathrm{~b}$ & $48,96 \mathrm{a}$ & 10,22 \\
Receita por hectare (R\$) & $2.752,92 \mathrm{a}$ & $2.463,13 \mathrm{~b}$ & 12,16 \\
Margem bruta (R\$) & $578,14 \mathrm{a}$ & $288,34 \mathrm{~b}$ & 10,43 \\
Margem líquida (R\$) & $433,91 \mathrm{a}$ & $144,12 \mathrm{~b}$ & $5,85 \mathrm{~b}$ \\
Lucratividade (\%) & $15,76 \mathrm{a}$ & & \\
\hline
\end{tabular}

Médias seguidas por letras distintas na linha diferem entre si pelo teste $\mathrm{F}(\mathrm{P}<0,05)$.

PC: peso corporal; UA: unidade animal (450kg de PC); CV: coeficiente de variação. 
Diante desses resultados, deve-se ressaltar a importância na deposição de gordura, tanto em animais castrados como não-castrados. A dieta na fase de terminação é um dos principais fatores relacionados à maior deposição de gordura, visando a animais acabados precocemente. Assim, torna-se necessário enfatizar a nutrição, visando a um maior acabamento de gordura, garantindo melhor aceitabilidade pelos frigoríficos.

Os animais não-castrados apresentaram maior margem líquida e lucratividade, tanto por animal como por área, sugerindo ser mais viável a sua criação. Entretanto, as características de carcaça não permitem a comercialização no mesmo valor pago para a arroba de boi, pois apresentaram acabamento de gordura escasso, inferior ao exigido pelo frigorífico ( 3 a $6 \mathrm{~mm}$ ). Tal fato sugere que, na fase de terminação, esses animais deveriam receber suplementação rica em energia visando à deposição de gordura na carcaça.

\section{CONCLUSÕES}

Conclui-se ser importante estudar alternativas para melhorar a deposição de gordura na carcaça de animais F1 Canchim-Nelore abatidos precocemente em pastagens. Sugere-se a utilização de animais não-castrados suplementados em pastagens de Brachiaria decumbens.

\section{REFERÊNCIAS BIBLIOGRÁFICAS}

AGUIAR, A.P.; ALMEIDA, B.H.P.J.F.; AMARAL, G.C. et al. Viabilidade econômica da produção de carne em sistemas intensivos de pastagens na região do cerrado. In: REUNIÃO ANUAL DA SOCIEDADE BRASILEIRA DE ZOOTECNIA, 38., 2001. Piracicaba. Anais... Piracicaba: Gmosis, 2001. (CD-ROM).

ANUÁRIO da Pecuária Brasileira. São Paulo: FNP Consultoria, 2002. 400p.

CLIMACO, S.M.; RIBEIRO, E.L.A.; MIZUBUTI, I.Y. et al. Desempenho e características de carcaça de bovinos de corte inteiros ou castrados e suplementados ou não durante o inverno. Acta Sci. Anim. Sci., v.28, p.209-214, 2006.

COSGROVE, G.P.; KNIGHT, T.W.; LAMBERT, M.G. et al. Effects of post-pubertal castration and diet on growth rate and meat quality of bulls. Proc. N. Z. Soc. Anim. Prod., v.56, p.390-393, 1996.

EUCLIDES, V.P.B.; EUCLIDES FILHO, K.; ARRUDA, Z.J. et al. Alternativas de suplementação para redução da idade de abate de bovinos em pastagem de Brachiaria decumbens. Campo Grande: Embrapa - Gado de Corte, 1997. 25p. (Circular Técnica, 25).

FEIJÓ, R.M.B. Análise econômica de dois sistemas de produção de carne bovina no cerrado do Mato Grosso do Sul: tradicional vs. semi-intensivo. 1999. 66f. Monografia (Bacharelado) - Universidade Católica Dom Bosco, Campo Grande, MS.

ÍTAVO, L.C.V.; SILVA, F.F. Aspectos produtivos da castração de bovinos de corte In: SEMANA DE CIÊNCIAS AGRÁRIAS DA UESB, Itapetinga, Anais... Itapetinga, 2001. p.33-74.

ÍTAVO, L.C.V.; TOLENTINO, T.C.P.; ÍTAVO, C.C.B.F. et al. Consumo, desempenho e parâmetros econômicos de novilhos Nelore e F1 Brangus-Nelore terminados em pastagens, suplementados com mistura mineral e sal nitrogenado com uréia e amiréia. Arq. Bras. Med. Vet. Zootec., v.60, p.419-427, 2008.

MULLER, L. Normas para avaliação de carcaça e concurso de carcaça de novilhos. 2.ed. Santa Maria: UFSM, 1987. 31p.

PAULINO, M.F.; DETMANN, E.; ZERVOUDAKIS, J.T. Suplementos múltiplos para recria e engorda de bovinos em pastejo. In: SIMPÓSIO DE PRODUÇÃO DE GADO DE CORTE, 2., 2001, Viçosa.. Anais... Viçosa, 2001. p.187-231.

PAULINO, M.F.; MORAES, E.H.B.K.; ZERVOUDAKIS, J.T. et al. Suplementação de novilhos mestiços recriados em pastagens de Brachiaria decumbens durante o período das águas: desempenho 1. In: REUNIẪ ANUAL DA SOCIEDADE BRASILEIRA DE ZOOTECNIA, 39., 2002, Recife. Anais... Recife, 2002. (CD-ROOM).

REEVES, J.J.; SHIMOKOMAKI, M.; RIBEIRO, E.L.A. et al. Growth and carcass characteristics of pasture fed LHRH immunocastrated, castrated and intact Bos indicus bulls. Meat Sci., v.68, p.285-290, 2004. 
RESTlE, J.; GRASSI, C.; FEIJÓ, G.L.D. Evolução do peso de bovinos de corte inteiros ou castrados em diferentes idades. Pesq. Agropec. Bras., v.29, p.1631-1635, 1994.

RESTlE, J.; GRASSI, C.; FEIJÓ, G.L.D. Características das carcaças e da carne de bovinos inteiros ou submetidos a duas formas de castração, em condições de pastagem. Rev. Bras. Zootec., v.25, p.334-344, 1996.

RESTLE, J.; FLORES, J.L.C.; VAZ, F.N. et al. Desempenho em confinamento, do desmame ao abate aos quatorze meses, de bovinos inteiros ou castrados, produzidos por vacas de dois anos. Cienc. Rural, v.27, p.651-655, 1997.

RESTLE, J.; VAZ, F.N.; ALVES FILHO, D.C. Machos não-castrados para a produção de carne. In: RESTLE, J. (Ed). Confinamento, pastagens e suplementação para produção de bovinos de corte. Santa Maria: UFSM, 1999. p.215-231.

RESTLE, J.; ALVES FILHO, D.C.; FATURI, C. et al. Desempenho na fase de crescimento de machos bovinos inteiros ou castrados de diferentes grupos genéticos. Rev. Bras. Zootec., v.29, p.1036-1043, 2000a.

RESTLE, J.; VAZ, F.N.; FEIJÓ, G.L.D. et al. Características de carcaça de bovinos de corte inteiros ou castrados de diferentes composições raciais. Charolês x Nelore. Rev. Bras. Zootec., v.29, p.1371-1379, 2000b

RIBEIRO, R.R. Análise comparativa entre três sistemas de formação de pastagens no cerrado do sul mato-grossense. 1999. 53f. Monografia (Bacharelado) - Universidade Católica Dom Bosco, Campo Grande, MS.

SEIDEMAN, S.C.; CROSS, H.R.; OLTJEN, R.R. et al. Utilization of the intact male for red meat production: a review. J. Anim. Sci., v.55, p.826-840, 1982.
SILVA, F.F. Aspectos produtivos da castração de novilhos de corte. Cad. Tec. Vet. Zootec., n.33, p.64-94, 2000.

SILVA, D.J.; QUEIROZ, A.C. Análise de alimentos: Métodos químicos e biológicos. 3.ed. Viçosa: UFV, 2002.

STEEN, R.W.J. The effect of plane of nutrition and slaughter weight on growth and food efficiency in bulls, steers and heifers of three breed crosses. Liv. Prod. Sci., v.42, p.1-11, 1995.

SISTEMA de análises estatísticas e genéticas SAEG. Viçosa: UFV, 1997. 59p.

VALADARES FILHO, S.C.; PAULINO, P.V.R.; MAGALHÃES, K.A. Exigências nutricionais de zebuínos e tabelas de composição de alimentos BR Corte. Viçosa: UFV, 2006. $142 \mathrm{p}$.

VAZ, F.N.; RESTLE, J.; PEROTTONI, J. et al. Aspectos qualitativos da carcaça e da carne de machos Hereford, inteiros ou castrados, abatidos aos quatorze meses. In: REUNIÃO ANUAL SOCIEDADE BRASILEIRA DE ZOOTECNIA, 36., 1999, Porto Alegre. Anais... Porto Alegre: SBZ, 1999, p.335.

VAZ, F.N.; RESTLE, J. Aspectos qualitativos da carcaça e da carne de machos Hereford, inteiros ou castrados, abatidos aos quatorze meses. Rev. Bras. Zootec., v.29, p.1894-1901, 2000.

VITTORI, A.; QUEIROZ, A.C.; RESENDE, F.D. et al. Características de carcaça de bovinos de diferentes grupos genéticos, castrados e nãocastrados, em fase de terminação. Rev. Bras. Zootec., v.35, p.2085-2092, 2006.

VITTORI, A.; GESUALDI JÚNIOR, A.; QUEIROZ, A.C. et al. Desempenho produtivo de bovino de diferentes grupos raciais, castrados e não-castrados, em fase de terminação. Arq. Bras. Med. Vet. Zootec., v.59, p.1263-1269, 2007. 